\title{
La evolución de la biología y la biología evolucionista: especie y finalidad
}

\section{The evolution of biology and the evolutionist biology: species and finality}

\author{
Daniel Labrador Montero \\ Universidad de Salamanca, España \\ danilabra@usal.es
}

\begin{abstract}
Resumen
¿Son las especies categorías reales o meras convenciones? ¿Son las especies clases naturales? ¿Son los enunciados teleológicos un rasgo distintivo de la biología como ciencia? Estas preguntas y otras muchas son una constante en la filosofía de la biología. En este artículo se pretende mostrar que difícilmente se puede dar respuesta a alguna de ellas sin adquirir una posición respecto a las otras, pues existe una relación histórica entre las cuestiones acerca del concepto de especie y las cuestiones acerca de la finalidad. Para escenificar dicho vínculo se acudirá a una perspectiva histórica, donde se indagará en el desarrollo de esta ligazón entre las nociones de especie y finalidad. El centro y desembocadura de este trabajo será la teoría darwinista. El objetivo, por tanto, es realizar dicho análisis hasta la teoría de Darwin.
\end{abstract}

Tras realizar este trayecto centrado en el pensamiento de Aristóteles, Linneo, Buffon y Lamarck, se examinará la peculiar postura de Darwin acerca de la teleología y la relación que esto tiene con sus ideas acerca de las especies. A pesar de que Darwin inicia la caída de los grandes esencialismos teleológicos dentro de la reflexión sobre lo vivo, hay rastros de un finalismo en su obra.

Palabras clave: teleología, adaptación, transformismo, selección natural, Darwin.

\begin{abstract}
Are species real categories or just conventions? Are species natural kinds? Are teleological statements a distinctive feature of biology? Can life sciences escape from teleology? These are common issues in philosophy of biology. This paper aims to show that in order to
\end{abstract}

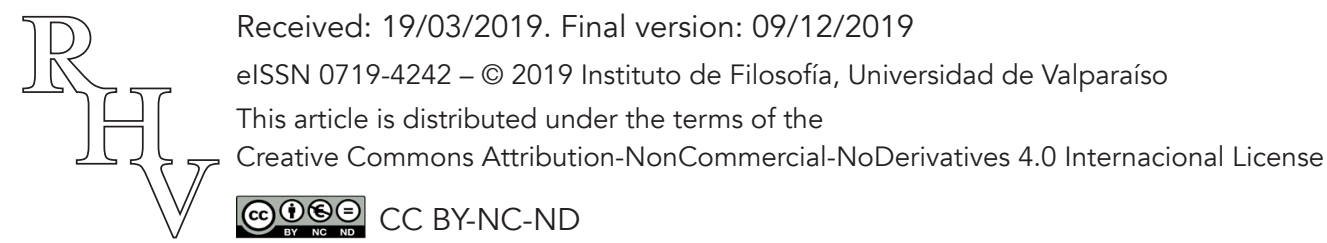


answer to each of these questions it is inevitable to take a position respecting the others. Therefore, there is a historical relation between the concept of species and teleological issues. In order to analyse such relation, I will take a historical perspective.

After making such historical reconstruction focused on the Aristotle, Linnaeus, Buffon and Lamarck thoughts, I will analyse the Darwinian peculiar view respect teleology and his ideas about species. Although Darwin set out the collapse of teleological essentialisms in biology, there are important vestiges of teleology in his theory.

Keywords: teleology, adaptation, transformism, natural selection, Darwin.

\section{Introducción}

El propósito de este artículo es analizar la relevancia histórica que ha tenido la relación entre las nociones de especie y de finalidad en el pensamiento biológico-filosófico hasta Darwin. Se intentará mostrar que la predilección por una teleología no (pre)determinada implica la apertura a la posibilidad de un transformismo que no dependa de teleologías fuertes. Es, por ello, que, en primer lugar, hay que detenerse en qué se considerará teleología y las diferentes formas que esta puede adoptar.

Es oportuno recalcar que el desarrollo de toda la argumentación está orientado a culminar con el pensamiento de Darwin y que, por tanto, no se irá más allá del siglo XIX. Analizar dichas relaciones en el neodarwinismo y la teoría evolutiva actual requeriría un artículo por sí solo. De esta forma, cualquier afirmación que se realice acerca de la teoría darwinista no tiene por qué ser aplicable a la biología actual, donde el panorama teórico es mucho más complejo.

\section{Las dicotomías teleológicas}

En la mayor parte de los campos del saber Aristóteles se mantuvo como referente durante siglos, autor finalista por excelencia. Toda su filosofía tiene como núcleo central una teleología naturalizada. Su derrumbe provino de la propuesta mecanicista, con el final del contemplativismo. Ya no era interesante admirar el inmenso plan de la naturaleza, sino saber cómo se desarrollaban sus procesos para poder reproducirlos artificialmente. La belleza de la naturaleza parecía desvanecerse de la mente científica con el rechazo de cualquier orden natural que aparentara una imposición antropomorfa. Así, formas y fines pasaron a ser ficciones que el hombre impone a la naturaleza ${ }^{1}$ (cf. Bacon 1984), pues la contemplación pasiva, predicaban, no ayuda a comprender el mundo, sino solo a admirarlo (Gilson 1980, 64).

${ }^{1}$ Cf. $\S 51$ del libro I de Novum Organum.

Revista de Humanidades de Valparaíso, 2019, No 14, 395-426

()ㅛ $\Theta \Theta$ CC BY-NC-ND 
Las ciencias de la vida, en cambio, no se deshicieron de la finalidad. Hoy siguen sin poder hacerlo, aunque no por falta de partidarios de su erradicación. ¿Por qué la teleología parece razón de ignominia dentro de las ciencias naturales? Tomando como base el trabajo de Ernst Mayr (1988), Antonio Diéguez resume a la perfección cuáles son los presupuestos que hay detrás del resquemor epistemológico hacia la teleología en las ciencias naturales:

1. Las explicaciones teleológicas introducen elementos antropomórficos en la explicación. Es como si se atribuyera a la naturaleza una especie de propósito o deliberación consciente que la lleva a poner los medios adecuados para la consecución de sus fines $[\ldots]$

2. El discurso teleológico invierte el orden causal aceptable científicamente, situando en el futuro la causa y en el presente el efecto. [...]

3. Los enunciados teleológicos no pueden ser contrastados empíricamente.

4. La teleología no está más que en la mente del observador. (Diéguez 2012, 175-176)

Sin embargo, pueden mantenerse explicaciones teleológicas sin recurrir a un agente externo o a causas finales. Además, como infiere Michael Ruse (1973, 213), "la biología tiene, en un sentido más amplio, un elemento teleológico intraducible (aunque quizá eliminable). De manera muy real, los biólogos alcanzan una intelección explicativa refiriéndose al futuro". Ruse se refiere a un finalismo sin causas finales, a una "teleología poco sólida", lo que supone abrir los ojos ante los diferentes modos de teleología.

Se argumentará, que el paso hacia un transformismo "científico" (sin suponer fuerzas especulativas) y hacia un nuevo concepto de especie en el siglo XIX implicó el paso de una teleología interna (pre)determinada a una indeterminada, es decir, de una finalidad en la que el estado final está predeterminado sin importar los eventos circunstanciales e históricos a otra en la que el estado final no está prefijado. En relación con esto, también se puede distinguir entre teleología intra-orgánica, propia de cada organismo en sí mismo "causalmente dirigida a la consecución de un objetivo predeterminado", y teleología adaptativa, esto es, la de un individuo para con su entorno (Caponi 2002, 59) ${ }^{2}$. Caponi toma la diferenciación de von Uexkull: "en los seres vivos adultos distinguimos una doble conformidad a fin: de un lado, cada organismo está construido conforme a un fin en sí mismo, y del otro, el organismo está adaptado conforme a fin a su entorno" (von Uexkull 1945, 175). El paso continuo al segundo tipo de teleología a partir del siglo XVIII allanará el camino a un transformismo y a un evolucionismo en el que las causas principales del cambio no sean impulsos teleológicos internos de los organismos o un telos externo predeterminado, lo que tendrá consecuencias radicales para el concepto de especie.

\footnotetext{
${ }^{2}$ Caponi utiliza esta dicotomía en referencia a la distinción de Ernst Mayr entre biología funcional y evolutiva. Espero que se me permita usar esta dicotomía para los fines expuestos.
} 
Lamarck no fue capaz de desarrollar una teoría transformista sin renunciar a la teleología fuerte o "sólida", pero la apertura al adaptacionismo que él llevo a cabo implicaba el primer reconocimiento de que los factores circunstanciales cumplían un papel en la evolución. Y es que parece inviable abrazar el transformismo sin otorgar al entorno algún rol en la causación y motivación de dichas transformaciones - a no ser que se establezca la intervención divina como fuente de una mutabilidad que armoniza las formas de los seres con sus entornos concretos-. Con esto no se quiere decir que el cambio hacia la teleología adaptativa sea un paso previo para impulsar el salto al transformismo, sino que son dos aspectos que se dan conjuntamente.

Mostrar esta imbricada unión entre teleología y todo lo que abarca el concepto de especie - el realismo y antirrealismo, el fijismo y transformismo, los principios sobre los que se sostiene, etc. - hasta Darwin será la tarea del presente texto. Para ello, haciendo honor a De Aristóteles a Darwin (y vuelta) de Etienne Gilson, se irá desde el autor griego al biólogo inglés, pasando principalmente por las figuras de Linneo, Buffon y Lamarck.

\section{La biofilosofía de Aristóteles: eidos, finalidad y realismo moderado}

La discusión acerca del concepto de especie en Aristóteles $^{3}$ ha sido ampliamente debatida. Fue a partir del artículo de David Balme (1962) que se llegó a cierto consenso acerca de la flexibilidad de los conceptos de género y especie. De acuerdo con Marjorie Grene (1974), el uso de los términos 'genos' y 'eidos' es, en cierto sentido, caótico, ligado al lenguaje común y cotidiano (Jiménez Sánchez-Escariche 2000, 15). Tampoco había en Aristóteles un proyecto complejo de ordenación taxonómica universal (Pellegrin 1987). Sus diferentes clasificaciones dependían, más bien, del objeto de estudio (morfología, fisiología, etc.). Cierto es que, en cuanto a ordenación lógico-sistemática, genos está por encima de eidos (cf. Aristóteles 2000, IA I, 486a24-26), y esto es algo que parece corresponderse con la actual relación entre las categorías de género y especie, que se instaló con facilidad en las ciencias naturales gracias a las ventajas que conllevaba para los fines clasificatorios (Jahn et al. 1990; Barberá 1994).

Esto no significa que se haya alcanzado algún tipo de acuerdo más allá de lo anteriormente expuesto, sobre todo en lo relativo a las consecuencias filosóficas y ontológicas de su propuesta. Lo que sí parece evidente es que Aristóteles utiliza el concepto de eidos en sus tratados biológicos fundamentalmente como forma (Balm, 1962), para designar un conjunto de rasgos característicos y comunes, esto es, esenciales (Barberá 1994). Y este esencialismo va unido irremediablemente a su fijismo, pues este eidos no es más que la posibilidad de eternidad que le es arrebatada a los individuos con la imposición de la vejez y la muerte (Papavero et al. 1995, 128). Como explica el estagirita, "la idea

\footnotetext{
${ }^{3}$ Abreviatras: $\mathrm{PA}=$ Partes de los animales; $\mathrm{DA}=$ Acerca del Alma; $\mathrm{IA}=$ Investigación de los animales; Met= Metafísica.
}

Revista de Humanidades de Valparaíso, 2019, No 14, 395-426 
creadora preexiste a su producto y es igual que él" (Aristóteles 2000, PA I, 640a29-30), luego, a través de la reproducción, los progenitores generan individuos esencialmente iguales, de tal manera que aquellas características formales se mantienen de generación en generación. Entre especies hay, por tanto, un muro antitransformista: la esterilidad. La mezcla de especies no parecía posible, y de las pocas excepciones resultaban seres "inferiores" y estériles.

No resulta extraño que esta idea fijista se mantuviera con fuerza hasta el siglo XIX, pues encaja a la perfección con el dogma cristiano de la creación perfecta, acabada e inmutable de la obra divina (Papavero et al. 1995, 129). De este modo, autores como Andrea Cesalpino en el siglo XVI o William Harvey (1651) recurrían a la noción aristotélica de traspaso de la forma o esencia de padres a hijos en el proceso de reproducción. Esta idea de una esencia transgeneracional o "concepción generativa de la especie" postula que hay un "poder generativo compartido" que define a la especie y determina al individuo (Wilkins 2010). En la filosofía aristotélica, esta esencia puede identificarse con el alma, como aquello que es propio y germen de la vida. El alma es forma, acto, entelequia (Aristóteles 2010, DA II, I, 412a10). El alma es esencia y definición de los seres naturales, es su telos. Es fácil apreciar, dicho esto, que el fijismo es inherente a tal doctrina, pues si el alma define a un ser vivo y es traspasada por el padre a través del semen, no cabe más que las especies sean inmutables.

Aún así, Aristóteles llega a una preconcepción de la adaptación, que se muestra en la relación que establece entre la funcionalidad de un órgano y la estructura y existencia de este. Así, en Acerca del alma infiere que, puesto que "la Naturaleza no hace nada en vano" (Aristóteles 2010, DA III, 12, 434a31), los animales, además del sentido del tacto necesario para sobrevivir, tienen los diferentes sentidos y órganos en dependencia de su función y utilidad en un entorno indicado (Aristóteles 2010, DA, 12, 434b). He aquí la belleza de la naturaleza, el acoplamiento de cada ser y parte a su finalidad, pues "en las obras de la naturaleza, en efecto, no existe el azar, sino el para qué de algo" (Aristóteles 2000, PA I, 654a24-25). Mas esta belleza no parece sensible, sino inteligible, admirable a través del poder de la contemplación racional. La influencia platónica queda patente, como bien explica Geoffrey Lloyd (1974), pues la ordenación de los seres y la pluralidad de estos están orientadas a un fin que es dado por naturaleza y que, por tanto, confluye con la Belleza y el Bien presentes en los procesos naturales. Es, por ello, que no se puede entender el concepto de especie sin percatarse de que ese eidos definitorio estipula un orden y atribuye un sentido natural.

En suma, hay dos características principales en el concepto de especie aristotélico: el fijismo y la sumisión de la causa eficiente sobre la final. Sirva de ejemplo el siguiente párrafo en cuanto a su conjugación:

Por eso Empédocles no tenía razón al decir que muchas características se dan en los animales por haberse producido durante el proceso de formación, [...]. Desconoce, en 
primer lugar, que el germen constituyente debe existir ya con tal potencialidad; luego, que lo que produce existe con anterioridad no sólo lógicamente, sino también temporalmente: así el hombre engendra un hombre, de modo que, al tener tales características aquél, el proceso de formación de este otro se produce de tal manera. (Aristóteles 2000, PA I, 640a20-27)

Este párrafo expresa con fuerza cómo cualquier proceso animal tiene su razón de ser en la esencia que define a la especie. Los procesos biológicos se dan para realizar la esencia prefijada e innata. Fin, logos, alma, esencia y causa final parecen identificarse aquí. Esto quiere decir que, si la esencia pasa de padre a hijo, también el propio telos y, por lo tanto, cualquier proceso natural ha de ser el mismo en cada generación. Se puede apreciar, por ende, que finalismo y fijismo son interdependientes en la biofilosofía aristotélica.

Por último, la oscuridad escenificada en la obra aristotélica respecto al uso en su teoría biológica de los términos 'genos' y 'eidos' converge con una cierta ambigüedad acerca del conocido problema de los universales. En ocasiones resulta difícil conjugar su esencialismo con su crítica al realismo radical de Platón acerca de los universales. El universal no puede ser sustancia o entidad, dice Aristóteles (cf. Aristóteles 2010, Met Z, 13). El universal es "común", es decir, pertenece a una pluralidad de cosas (cf. Aristóteles 2010, Met Z, 13, $1038 \mathrm{~b} 8$ y ss.), pero se encuentra in re y depende, por tanto, de los individuos particulares. No hay dos individuos iguales por más que existan las esencias.

Muchos son los que consideran la postura de Aristóteles como un realismo moderado. En verdad, el filósofo griego quiere huir de la teoría de las Ideas platónica, donde se da un salto injustificable de lo epistemológico a lo ontológico al considerar lo universales como preexistentes a los objetos particulares porque se accede a los primeros a través de la ciencia y de la razón, mientras que los segundos quedan relegados a la percepción sensible. A pesar de que para Aristóteles el conocimiento humano es siempre de lo universal, no da un salto afirmando un estatus ontológico supremo para los universales al modo que lo hace Platón. Los universales existen en la medida que son "expresión sustancial" de los individuos (Boecio 2010, Segundo Comentario a la Isagoge 1.11.14), pero sin individuos particulares no podrían existir.

A modo de resumen, se puede concluir lo siguiente: 1) el uso no actual y estricto de los términos 'genos'y 'eidos' por parte de Aristóteles; 2) el fuerte finalismo de su biofilosofía es indesligable de su fijismo y 3 ) detrás de esta teoría finalista hay un realismo moderado esencialista respecto a las especies.

\section{La era de la taxonomía: Linneo y Buffon}

Tras una Edad Media en la que el pensamiento biofilosófico quedó relegado a un segundo plano, la Edad Moderna y la Ilustración abrieron paso a un creciente interés naturalista y trabajo clasificatorio, a lo que contribuyó la riqueza natural del nuevo 
continente descubierto. Sí hubo, sin embargo, en el ámbito filosófico, un fuerte debate medieval acerca de la naturaleza de los universales que resulta, cuanto menos, de interés adyacente a la noción de especie. La definición de universal propuesta por Aristóteles como lo común a una multiplicidad fue tomada de forma indirecta por Severino Boecio a través de Porfirio (cf. Boecio 2010, Segundo comentario a la 'Isagoge' de Porfirio, 1.10.13). Las apreciaciones de Boecio tuvieron gran influencia a lo largo de la Edad Media. Para este, los universales no existen realmente en el mundo, pero tampoco son meras abstracciones mentales (Espinal 2011, 381).

Es interesante señalar para después analizar las posturas de Linneo y Buffon en torno a la realidad ontológica de las especies que, frente a los diferentes realismos, surgió una posición nueva: el nominalismo. Fue Roscelino quien inauguró esta corriente que toma los universales por flatus vocis, por convenciones lingüísticas que reúnen lo común de entes individuales pero que carecen de existencia ontológica. Sin embargo, la perspectiva nominalista vio su consolidación en el antirrealismo de Pedro Abelardo, que en esta discusión medieval moderó la postura radical de Roscelino. Los universales dejan de ser meras voces para adquirir un sentido lingüístico-semántico con Abelardo: los universales tienen sentido en un leguaje compartido (García-Encinas 2005, 181).

Ahora bien, ¿existe algún reflejo de estas reflexiones en los naturalistas del siglo XVIII? El análisis de los universales sirve para conectar con el pensamiento de Linneo y Buffon acerca de la realidad y naturaleza de las especies, lo cual quedará reflejado en los siguientes párrafos.

Linneo dominó el panorama de la biología durante su siglo por ser un "trabajador incansable" que tenía muy en cuenta las necesidades de la ciencia de su época (Blunt 1982, 11). Como un segundo Adán ${ }^{4}$ (Harrison 2009), se otorgó la tarea de nombrar a los seres vivos. La analogía resulta oportuna por el gran sentido religioso patente en la obra del autor sueco, donde ciencia y teología natural diluyen sus fronteras. Esto es algo observable ya en la primera tabla de su Systema Naturae. Allí, en Observaciones sobre los tres reinos de la naturaleza parece afirmar que el Creador ha dotado al hombre de sensibilidad e intelecto para admirar la majestuosa obra natural:

Thus I wonder why the Creator put man, who is thus provided with senses and intellect, on the earth globe, where nothing met his senses but natural objects, constructed by means of such an admirable and amazing mechanism. Surely for no other reason than the observer of the wonderful work might admire and praise its Maker. (Linneo 1964, 18)

Sin embargo, esta admiración intelectual requiere de tiempo y necesita del clasificador y descriptor para poder darse de forma efectiva. Al identificar la naturaleza con la obra de Dios le da una finalidad — ser admirada - y un sentido al ser humano: adorarla y

\footnotetext{
${ }^{4}$ Acusación de Johann Stöver en una carta de 1746.
} 
desentrañar los mecanismos de esta (Gilson 1980, 87). Pero, más allá de esto, parte de la asunción de que todos los seres naturales son "obra de Dios" y que todos provienen de un huevo de donde surge una cría semejante al padre. Esto concluía en su postura fijista con claro eco aristotélico:

As there are no new species (1); as like always gives birth to like (2); as one in each species was at the beginning of the progeny (3), it is necessary to attribute this progenitorial unity to some Omnipotent and Omniscient Being, namely God, whose work is called Creation. This is confirmed by the mechanism, the laws, principles, constitutions and sensations in every living individual. (Linneo 1964, 18)

En el párrafo anterior no solo se afirma que las especies se mantienen debido a que cada ser produce uno similar, sino que también se alude a la especie como unidad que gobierna el orden. Esto último le adhiere al realismo y a la concepción generativa de la especie. Las especies son inamovibles, clases naturales — al menos para el primer Linneo ${ }^{5}$ y "la generación supone la continuidad de las formas" y, por tanto, la discontinuidad entre especies (Álvarez López 1948, 15). Las clases naturales tienen como principal característica la perpetuidad de sus propiedades (Ruse 1987, 229). Por ello, la especie será también la unidad taxonómica de Linneo, y su inmutabilidad es un axioma necesario para cualquier clasificación. Y la clasificación era imprescindible, a su vez, porque todo verdadero conocimiento natural dependía de conocer las especies (Larson 1971).

El fijismo de Linneo ya es evidente en su obra temprana: en Genera Plantarum (1737) ya se refleja algo muy parecido a su famosa sentencia "Species tot sunt, quot diversas formas ab initio produxit Infinitium Ens"6 (Linneo 1780). La suposición de un creador intencional daba irremediablemente un carácter (pre)determinado a la teleología de Linneo. Las especies, generadas por obra divina, tienen como fin el que Dios les haya impuesto.

El éxito de la clasificación linneana tiene, también, motivos circunstanciales. Su oportunismo es innegable, "pues desde el Renacimiento se habían reunido tantas plantas europeas y extraeuropeas que ya se hacía indispensable alguna guía que permitiera ordenarlas" (Papp y Babini 1958, 77). Como bien señala Ernst Mayr, "las clasificaciones son necesarias dondequiera que uno tenga que lidiar con la diversidad" (Mayr 2000, 147, traducción propia), y esa diversidad se hizo demasiado grande con la recolección natural en los nuevos mundos. Pero este afán taxonómico no era compartido por todos sus coetáneos. Linneo, fiel expresión del realismo y un sistemático obsesivo, tiene su antagonista en Buffon, un antirrealista convencionalista y asistemático (Diéguez 2012,

\footnotetext{
${ }^{5}$ El esencialismo de Linneo se va diluyendo con el paso de los años. Ya en 1755, en su Metamorphosis plantarum, duda acerca de la inmovilidad de las especies. Se abre, así, un período de conflicto entre su fe creacionista y sus observaciones, que descartaban el fijismo.

6 "Hay tantas especies como formas distintas creó inicialmente el Ser Infinito” (traducción propia).
} 
210). Buffon, cansado de ver cómo el lenguaje de la ciencia se hacía más difícil que la propia ciencia, afirmaba que no existen más que los individuos y que las clasificaciones no son más que categorizaciones humanas que introducen a la fuerza el mundo vivo en cajones demasiado estrechos. En un arrebato nominalista declaraba: “¡Sólo un montón de nombres, nada más!" (Papp y Babbini 1958, 118). Tal enemistad era manifiesta: "Buffon detestaba las clasificaciones, los clasificadores y, más que a ningún otro a Linneo" (Gilson 1980, 90).

De forma contraria a Linneo, Buffon se vio incapaz de afirmar la discontinuidad entre especies, pues estas no están delimitadas de forma precisa, existen cantidad de eslabones intermedios que no permiten dividir concisa y tajantemente a las diferentes especies:

Pero la naturaleza opera por gradaciones desconocidas, y, por consiguiente, no puede prestarse totalmente a estas divisiones, ya que pasa de una especie a otra especie, y con frecuencia de un género a otro, por matices imperceptibles; de modo que existe un gran número de especies medias y de objetos semipartidos que no se sabe dónde colocar, y que, necesariamente, perturban el proyecto de un sistema general. (Buffon 1884, 370, traducción propia)

Es algo palmario, para Buffon, que los órdenes y los géneros son instrumentos artificiales y propios de la imaginación humana, rara vez útiles. Linneo no conocía la verdadera naturaleza de las especies y, por tanto, acudía a definiciones dogmáticas para realizar su sistema, consideraba el autor francés (Perrier 2009, 47). Sin embargo, también es cierto que había cierta oscilación respecto a su postura acerca del concepto de especie. El problema de los universales no fue algo cerrado en la mente de Buffon. Era incapaz de afirmar la realidad ontológica de las especies, pero tampoco podía prescindir de ellas. Buffon tuvo que quedarse a medio camino y, a la vez que afirmaba que las especies no existen, tenía que asumir que "ningún individuo existe fuera de una especie" (Gilson 1980, 94).

Por otro lado, sin llegar a dar jamás el paso transformista que daría Lamarck, Buffon asumió la variabilidad provocada generalmente por las circunstancias climáticas y alimenticias. Abre, así, el camino a la teleología adaptativa quedándose al inicio de este. Sin embargo, este cambio cualitativo no interrumpía el prototipo permanente de la especie. En otras palabras, afirma el transformismo, pero interno a las propias especies.

Buffon caminaba entre lo clásico y lo innovador. Por un lado, la idea de la scala naturae ronda toda su obra, y aunque ha sido un común denominador desde Aristóteles, en el francés adquiere una importancia muy notable. En el escalafón más alto estarían los hombres, que son cualitativamente diferentes de los animales: "el hombre no es un simple animal, como su naturaleza es superior a la de los animales, tenemos que trabajar para demostrar la causa de esta superioridad" (Buffon 1749-1788, tomo IV, 5) (traducción propia). Ahora bien, lo original de su escala natural es que presupone la continuidad: "no 
hay delimitación clara entre animales y plantas", solo entre seres vivos y no vivos (Alsina 2013, 78). Buffon tiene ya en mente el transformismo, pero reniega de ello obnubilado por la semejanza estructural y vital del mundo animal. Así, el asno no sería más que la degeneración del caballo.

Además de esto, Buffon, en su volumen V de la Historia Natural pone en cuestión que la naturaleza opere a través de causas finales, pues ofrece órganos sin ninguna utilidad (sirva de ejemplo los dedos de los cerdos o las tetillas de los machos), lo cual refuta aquel gran principio aristotélico que afirma la utilidad de todos los órganos. Otra de las razones para no confiar en el finalismo es que la naturaleza no parece hacer siempre lo más conveniente y funcional (Caponi 2012, 45). Caponi recoge un pasaje maravilloso donde Buffon muestra su antirrealismo, esta vez, hacia la causa final:

Todo aquello que no se daña a sí mismo al punto de destruirse, todo aquello que puede subsistir conjuntamente, subsiste; y puede ser que, en la mayoría de los seres, haya menos partes relativas, útiles o necesarias, que partes indiferentes, inútiles o superabundantes. Pero como siempre queremos reportar todo a un fin, cuando las partes no tienen usos aparentes, les atribuimos usos escondidos, imaginamos relaciones que no tienen ningún fundamento, que no existen en la naturaleza de las cosas, y que sólo sirven para oscurecerla: no percibimos que alteramos la filosofía, que desnaturalizamos su objeto, que es conocer el cómo de las cosas, la manera de actuar de la naturaleza; y substituimos ese objeto real por una idea vana procurando adivinar el porqué de los hechos, el fin que ella se propone al actuar. (como se cita en Caponi 2012, 46)

Esto no solo arremetía contra el funcionalismo de las partes, sino que también atacaba otro principio aristotélico ya mencionado supra, a saber, el de la naturaleza no hace nada en vano. En concreto, está refutando aquella noción de ser organizado, que Kant (2011, §66) afirma en su Crítica del Juicio y Georges Cuvier consolida con su Principio de la correlación de las partes en los seres organizados: "todas sus partes [de todo cuerpo organizado] tienen una acción recíproca que las une por encima de todas las demás y contribuye a un fin común, que es el mantenimiento de la vida" (Cuvier 1798, 5) (traducción propia). Como se puede apreciar, es difícil separar tal principio de una cierta concepción finalista, pues muestra una imagen del individuo como absolutamente dependiente de una estructura esencial de la especie en la que ya están impresas las funciones y fines de cada parte del organismo, el cual actúa como un todo gracias a tal equilibrio sistémico.

Esta lucha entre antirrealismo y realismo continuaría durante las siguientes décadas. El finalismo, por su parte, seguirá acompañando al concepto de especie. Lejos de morir con el mecanicismo, la teleología va adquiriendo nuevas formas, se adapta a las diferentes teorías, se sofistica con las diferentes observaciones. Al incluir el factor externo o ambiental como una de las causas del estado actual de las especies, el finalismo adquirirá un carácter más circunstancial. En la biología aristotélica los fines son fijos, un órgano cumple una función y es así siempre por naturaleza. Por esta razón, las especies han de ser inmutables. 
Sin embargo, el transformismo y la aceptación del influjo del entorno necesariamente socavan la invariabilidad de los fines. La relación del medio ambiente con la modificación del individuo será esencial, por tanto, para el origen del transformismo, pero también para un finalismo no predeterminado desde el comienzo, para un finalismo no fijo.

\section{Un evolucionismo finalista: las ideas de Lamarck}

Durante la primera mitad del siglo XX, fijismo y transformismo tuvieron en Cuvier, Saint-Hilaire y Lamarck una de sus mayores disputas. El transformismo evolucionista de este último resultaba algo rompedor, tanto que fue condenado a la desatención de sus coetáneos. A pesar de que Lamarck contaba con un cierto número de predecesores evolucionistas, él fue el primero en conformar esas ideas en una teoría estructurada. Ya Anaximandro estaba convencido del origen marino de toda la fauna y de cómo a partir de estos animales acuáticos evolucionaron el resto, incluido el hombre (Mayr 2000, 301302). Sin embargo, como nota curiosa, las ideas más parecidas a las de Lamarck aparecen en Zoonomia or Laws of Organic Life de Erasmus Darwin ${ }^{7}$ (1794), abuelo de Charles, aunque no se tiene constancia de que el francés conociera tal obra.

Aunque hay una serie obvia de antecesores, las ideas de Lamarck probablemente provengan de sus observaciones y trabajos como clasificador (Lamarck fue fijista hasta 1794). Precisamente, fue este ámbito el que más reconocimiento le otorgó, pero no mostró dubitaciones a la hora de afirmar su postura antirrealista respecto a las especies y demás categorías, cuya función pragmática, eso sí, es indudable:

Nada ha hecho la Naturaleza semejante, y para no engañarnos confundiendo nuestras obras con las suyas, debemos reconocer que las clases, los órdenes, las familias, los géneros, las nomenclaturas respecto de ella constituyen medios de nuestra invención, de los cuales no podríamos prescindir, pero que es forzoso emplear con discreción. [...] Pero tales clasificaciones [...] son medios artificiales en absoluto. [...] la Naturaleza no ha formado realmente ni clases, ni órdenes, ni especies constantes, sino solo individuos que se suceden los unos a los otros y que se asemejan a los que los han producido. (Lamarck 1986, 27-28)

Lamarck asevera que existe un mismo orden, indivisible, continuo, sin saltos. Esto se puede apreciar, según él, a través de uno de sus métodos principales: la analogía entre los diferentes individuos, que muestra cuán borrosas son las líneas divisorias de las clasificaciones (Lamarck 1986, 29). Esta noción continuista encaja a la perfección con un transformismo radical; aquel que Buffon no se atrevió a aceptar. El principio de la

\footnotetext{
${ }^{7}$ Para un mayor acercamiento a la obra de Erasmus Darwin y a sus tesis más importantes se recomienda la sección XXXIX de su Zoonomia disponible en https://archive.org/details/zoonomiaorlawsof1794darw. Para una aproximación al pensamiento de Erasmus Darwin sin pasar por su extensa obra, se recomienda la obra de Samuel Butler (1948), donde además se muestran las ideas de Erasmus en comparación con las de Buffon, Lamarck y su nieto Charles Darwin.
}

Revista de Humanidades de Valparaíso, 2019, No 14, 395-426 
continuidad progresiva, ya presente en la escala natural de Aristóteles, y la teoría de la evolución lamarckiana son algo inseparable, pero esta vez la escala dejó de tener forma lineal para adquirir forma de árbol con numerosas ramificaciones que culminan con el hombre (Lamarck 1986, 54). Esta continuidad tiene como núcleo central un principio que es común denominador en muchos transformistas - sobre todo en Spencer- ya presente en Aristóteles: lo simple es el origen de lo complejo. Sobre la génesis de lo simple, Lamarck acude a la generación espontánea como respuesta.

Ahora bien, más allá de la importancia que tiene no dar una respuesta teológica al origen de la vida, el punto central es discernir cómo es posible ese progreso de lo simple a lo complejo. Sin duda alguna, la respuesta del naturalista francés a esta cuestión revela un finalismo sin precedentes desde el estagirita. Existe una tendencia en lo vivo a la complejidad, una propensión de la naturaleza al perfeccionamiento. Pocas conclusiones pueden desvelar una teleología tal. Toda tendencia supone no solo un fin al que tender, sino un fin activo o causal que impele su búsqueda. Las fuerzas naturales y los impulsos de la materia viva son los principales promotores del cambio, pero, si estos fueran los únicos motores, la escala natural sería lineal. La razón por la que esta es ramificada se debe a las causas externas, es decir, circunstanciales, medioambientales. De esta forma, la modificación del entorno supone, en muchas ocasiones, un cambio en las necesidades de los seres vivos que viven en él. Esta modificación de las necesidades lleva irremediablemente a que los animales varíen sus hábitos. Si los nuevos hábitos implican, de forma prolongada, la utilización de un órgano o, por el contrario, una disminución del uso de otro, estos se verán alterados por tal situación. El uso de un órgano lo fortifica, lo impulsa para su desarrollo; el desuso todo lo contrario. Incluso, afirma que a través de estos "esfuerzos de la sensibilidad interior", pueden surgir órganos nuevos que antes no estaban, al igual que el desuso prolongado puede llevar a su desaparición. Estos cambios son heredables, tal que, tras muchas generaciones, los organismos están cada vez mejor adaptados a las nuevas circunstancias.

Lo verdaderamente importante de lo anterior es que en lugar de ser los órganos los que determinan las costumbres o hábitos de los seres vivos, son estos últimos, esto es, su forma de vida, la que, en relación con las circunstancias ambientales, ha determinado en un período extenso de tiempo la existencia o no de determinados órganos y, por tanto, las diferentes formas corporales. Nada de esencias fijas, nada de inmovilismo; el concepto de especie propio del fijismo no tiene sentido ante tales afirmaciones y, con ello, menos sentido tenía aún una postura realista acerca de la existencia de las categorías taxonómicas. La constancia de las especies parece tal ante la mirada limitada del ser humano, cuya historia no abarca lo suficiente para ser consciente de los cambios de la naturaleza. Pero incluso tomando a las especies de forma estática en su estado actual, la delimitación de estas es imperfecta e imposible a nivel completo. De esta forma, el concepto de especie que propone Lamarck —el cual solo tiene valor práctico, pero no 
ontológico - ha de añadir la cláusula circunstancial, es decir, los individuos se mantienen semejantes siempre y cuando las condiciones de vida no cambien tanto como para variar los hábitos de los individuos.

Se puede observar con claridad el carácter capital de las costumbres, que componen algo así como una segunda naturaleza (Gilson 1980, 106). En la teoría de Lamarck, tanto las necesidades como los hábitos tienen un carácter mediador entre la naturaleza y los individuos, entre el medio ambiente y los órganos que se relacionan con él. El cambio en el medio no provoca directamente el cambio de los organismos, sino nuevas necesidades a las que van asociados nuevos hábitos para satisfacerlas. Son estos nuevos hábitos los que implican un uso o desuso de determinados órganos o un esfuerzo para usarlos.

Ahora bien, más allá del principio teleológico que supone la dinámica natural hacia lo complejo, en esta interacción entre medio ambiente e individuos hay un finalismo que Gilson $(1980,107)$ se encargó de evidenciar: "como consecuencia inevitable, y sin embargo inesperada, el transformismo de Lamarck acaba en un derroche de finalismo. [...] los órganos nacen, crecen y se forman ellos mismos a fin de satisfacer las necesidades del organismo". Los órganos tienen su razón de ser en su finalidad, en su objetivo de solventar una necesidad. "Los pájaros no vuelan porque tengan alas, sino que tienen alas a fin de volar" (Gilson 1980, 112).

Llegados a este punto, es oportuno subrayar que, como se puede apreciar, para Lamarck existen dos fuerzas principales del cambio que se nutren de conceptos diferentes (cf. Gould 2002, 175-186). La primera de ellas tiene como base los conceptos de adaptación y entorno que se sustentan sobre un firme funcionalismo. La conformación de los organismos a los cambios del entorno supone una verdadera apertura al adaptacionismo. Sin embargo, en vista de que la historia ambiental no tiene dirección para el francés, necesitaba acudir a otra explicación para su arraigada tesis de la escala progresiva de seres. Si los entornos cambian sin fin alguno, la adaptación a estos no puede reflejar ningún tipo de cambio progresivo. De ahí la gran necesidad e incluso preminencia de la segunda fuerza, la tendencia a la ordenación compleja, sustentada sobre los conceptos de progreso, escala y jerarquía. Este es un caso paradigmático de teleología predeterminada e intraorgánica.

Ahora bien, aunque haya cierta prevalencia de la teleología predeterminada y la adaptación quede relegada a un segundo plano, no hay que restar importancia a la gran apertura hacia al adaptacionismo que Lamarck llevó a cabo. De hecho, el concepto de adaptación en el entramado teórico de Lamarck tuvo tanto peso en su creatividad teórica, como convincentemente argumentan Corsi (1988) y Gould (2000), que llegó a la noción de su mecanismo progresivo a partir de las ideas formuladas previamente sobre la adaptación. Y toda adaptación, en su caso, es difícilmente emancipada de una teleología.

Cabe preguntarse si la adaptación basada en este mecanismo del uso y desuso es de verdad semejante al concepto que se establece a partir del darwinismo. No cabe duda, que 
si se lee detalladamente la argumentación de Lamarck se encuentran claras diferencias con lo que Darwin entendía por adaptación. La explicación a las trasformaciones que propone Lamarck se produce como una respuesta a las circunstancias, aunque mediada por los hábitos. El hecho de que a través del uso o desuso se desarrolle o atrofie un órgano señala solamente que se ha utilizado o no o que se ha hecho o no el esfuerzo por hacerlo. Lamarck ofrece una explicación basada en un mecanismo de respuesta de los individuos ante la situación. En este aspecto parece, más bien, un "buffoniano radical" (Caponi 2006): el entorno simplemente cambia, "degenera", desvía a los seres al cambiar sus hábitos. Esto desvela, en definitiva, que, para Lamarck, el solo mecanismo a través del cual los seres se ven influidos por el medio no hubiera sido suficiente para llegar a la complejidad, verdadera meta de lo vivo.

En definitiva, en la obra de Lamarck hay una mezcla clara y contundente entre dos finalismos: uno necesario o determinado, dirigido a un fin, proveniente de una naturaleza que tiende a lo complejo desde sus orígenes; pero también uno más de corte adaptativo e indeterminado, que proviene de la interacción entre individuo y entorno y su preservación por la transmisión hereditaria. Este último sería no dirigido y es inherente a una postura transformista compleja. Sin embargo, la existencia del humano como cumbre de la escala natural y la gran diversidad de complejidad que encontramos en el mundo de lo vivo parece indicar que hay una cierta subordinación del segundo respecto al primero. De ahí que, aunque no sea linealmente, sino de forma ramificada, el plan de la naturaleza hacia lo complejo termina por cumplirse, sin que los cambios circunstanciales supongan un obstáculo definitivo para tal propósito. Por ende, ciertamente, la teleología adaptativa en Lamarck está subordinada a un fin predeterminado. No obstante, el naturalista francés realizó un paso crucial, a saber, vincular la adaptación con la transformación al poner la función como causa de la estructura. Así, la teleología adaptativa mostraba sus primeros brotes.

\section{Darwin, la teleología adaptativa y la caída del esencialismo}

En el presente apartado se intentará mostrar que es Darwin el que consigue dar el paso definitivo hacia una teleología adaptativa gracias al mecanismo de la selección natural. De esta forma, el concepto de especie tomó el desvío final hacia el transformismo $\mathrm{y}$, también, hacia un cierto antirrealismo, al no haber clases naturales fijas que poder discernir. Sin embargo, en el apartado 6 se argumentará que, pese a este movimiento de Darwin, existen ciertos elementos de su teoría que todavía guardan un poso de finalismo predeterminado y que, además, provocarán inclinaciones realistas que entrarán en tensión con el antirrealismo en ocasiones promulgado.

A lo largo de la historia natural, las tesis adaptacionistas pre-darwinianas son verdaderamente escasas. Hasta el asentamiento de la doctrina darwinista, "cada ser vivo tenía una función a cumplir y no un lugar a conquistar y a defender” (Caponi 2006, 10).

Revista de Humanidades de Valparaíso, 2019, No 14, 395-426

(c) $(9)(9)$ CC BY-NC-ND 
Realmente, antes de la irrupción del Origen de las especies (1859) y, sobre todo, hasta los años 40 del pasado siglo, el tema de la relación entre los rasgos morfológicos de los seres vivos y su medio no ocupaba un espacio privilegiado en la disciplina naturalista. Lejos de ser un tema digno de controversia, la relación entre las estructuras orgánicas y su entorno se tomó en sus inicios como prueba o evidencia empírica del plan divino. Así lo fue para John Ray, Linneo o William Paley. El mirífico orden de la naturaleza, la asombrosa economía animal y natural y la intricada conjugación de todos los elementos de los sistemas ecológicos era más fácilmente atribuible a un origen suprasensible y director que a uno inmanente y no intencional. Por otro lado, la verdadera meta de Lamarck, pese a la importante apertura que realizó, tampoco era el adaptacionismo, sino justificar su escala natural basada en la tendencia a lo complejo.

Escapar de esto fue la verdadera revolución de Darwin: desvincular la adaptación de cualquier designio, orientación o plan dirigido intencionalmente y dar un verdadero carácter útil a las adaptaciones. No hay una preordenación de la evolución, tampoco hay un sentido o dirección en ella, no va de lo simple a lo complejo, no cambia lo imperfecto por algo más perfecto. ¿Esto significa que Darwin dio con la fórmula para acabar con la teleología en biología? Cierto es que algunos vieron en Darwin al Newton de la brizna de hierba, un nuevo mesías mecanicista. Pero esto está lejos de cualquier pretensión que él tuviera. Prueba de ello es su asentimiento ${ }^{8}$ a aquella afirmación de Asa Gray (1874, 81): "let us recognise Darwin's great service to Natural Science in bringing back to it Teleology: so that instead of Morphology versus Teleology, we shall have Morphology wedded to Teleology". El trabajo de James Lennox (1993) demuestra a la perfección que Darwin no rehuyó de la finalidad, a pesar de que su teleología era particular, seguramente muy diferente de lo que entendía por ello el propio Asa Gray. La explicación darwiniana está lejos de cualquier teleología trivial. En consecuencia, es necesario hacer un análisis de algunos aspectos de su teoría para poder entender correctamente la teleología darwinista.

Hasta el darwinismo, la relación entre el ambiente y los seres no iba mucho más allá de la propuesta buffoniana de los efectos del clima y la alimentación (Caponi 2006). Más que adaptación, esto parecía revelar una aclimatación. El gran valor de Darwin fue su capacidad para explicar el transformismo a través de un mecanismo terrenal y coherente con sus observaciones. Uno de los rasgos principales y continuos en su teoría es su gradualismo: las diferentes características de los individuos obedecen a un proceso gradual. Este curso paulatino y continuo necesita de tres principios fundamentales (Lewotin 1982): variación, herencia y selección natural.

En su The Variations of Animals and Plants under Domestication, Darwin expresa de forma maravillosa que no existe relación alguna entre las variaciones generadas por las leyes de la naturaleza en los seres vivos (las cuales admite son fijas e inmutables) y

\footnotetext{
${ }^{8}$ La respuesta de Darwin a Asa Gray se puede consultar en el siguiente enlace: https://www.darwinproject. ac.uk/letter/DCP-LETT-9483.xml.
} 
la utilidad que estos pueden obtener de ellas en un entorno determinado. Es igual que si un constructor utiliza solamente piedras caídas por un precipicio sin ser estas cortadas y modificadas por el ser humano, es decir, su forma accidental depende únicamente de leyes naturales, como la ley de la gravedad o la erosión del viento. La utilidad que encuentra el constructor en dichas piedras nada tiene que ver con las leyes naturales que las han deformado (Darwin 1868, 263). Si se sigue con la analogía, el arquitecto encontrará algunas de esas piedras útiles para su construcción y otras las desechará por no tener las condiciones necesarias para la edificación que quiere realizar. Esto es lo que sucede con la selección natural, pero sin constructor que elija y compare. Por tanto, aunque las variaciones son requisito necesario para la adaptación, no son suficiente, puesto que no surgen con un objetivo. Por ello, es necesario un mecanismo que haga la criba, que permita a lo útil mantenerse. Este mecanismo es la selección natural.

Es de esta manera que aquellas variantes más aptas y, por lo tanto, con rasgos adaptativos, pasan de generación en generación y se extienden. La selección natural es el principal motor del cambio (aunque no el único) dentro de las especies —al ser el mecanismo gradual a través del cual unos rasgos triunfan sobre otros al triunfar los individuos que los portan - y la herencia es la forma en la que se mantienen. Es fácil apreciar, después de esto, que mientras Lamarck explicaba a través de la interacción entre el individuo y su entorno el surgimiento de los rasgos adaptativos, Darwin, a través de esa interacción, explica el triunfo y extensión de dichos rasgos, pero no el origen de las variedades como tal. Darwin afirmaba que las variaciones eran aleatorias, con lo cual quiere decir dos cosas: que su causa es desconocida y que no hay un finalismo detrás del surgimiento de las diferentes variedades, es decir, que no hay relación entre la génesis de las variaciones y las posibles utilidades que pueden tener en el entorno, a diferencia de la postura lamarckiana (Sober 2003; 2011). En definitiva, no media la necesidad entre el ambiente y el rasgo adaptativo. Las variaciones se dan sin responder a fin alguno. Darwin no pudo dar con la causa de tales variaciones, pero era algo totalmente observable que efectivamente se daban en las diferentes poblaciones. Y no solo eso, sino que, a través de la comparación, afirma, parece que son las mismas leyes las que obran en las variaciones más pequeñas y en las mayores diferencias (Darwin 1988, 213).

Aunque Darwin no podía explicar el motivo de dichas variaciones, sí podía justificar su heredabilidad (la selección artificial lo demostraba) y podía argumentar su implicación en la reproducción diferencial a través del principio de la selección natural:

[...] si las variaciones útiles a un ser orgánico ocurren alguna vez, los individuos caracterizados de este modo tendrán seguramente las mayores probabilidades de conservarse en la lucha por la vida, y, por el poderoso principio de la herencia, tenderán a producir descendientes con caracteres semejantes. A este principio de conservación o supervivencia de los más adecuados lo he llamado selección natural. (Darwin 1988, 179)

Revista de Humanidades de Valparaíso, 2019, No 14, 395-426 
La reproducción diferencial se da porque los rasgos adaptativos cumplen una función que permite a los individuos que los poseen tener una mejor posición en su interacción con el medio. La selección se produce sin seleccionador, las variaciones no responden a un fin. ¿Dónde está entonces la teleología? Algunos han respondido que su lenguaje (metafórico o no) implica tratar a la selección natural no tanto como el resultado del proceso anteriormente indicado, sino como una especie de causa o fuerza activa. Sin embargo, no es en este lenguaje metafórico - al menos en el sentido más importantedonde reside el componente teleológico de la explicación darwinista ${ }^{9}$. Darwin elimina la teleología predeterminada del principio de selección natural — no existe un fin que origine las variaciones, tampoco hay una causalidad retroactiva-, pero el hecho de que se mantengan unas y otras queden relegadas a la extinción solo puede ser explicado, como explicita Caponi (2003), bajo una estructura explicativa de problema-solución irreductible a una explicación "causal humeana". Por tanto, esta estrategia de explicación supone una cierta perspectiva teleológica, solo que indeterminada y adaptativa. Sin apelar a un designio ni a una causalidad retroactiva, la pregunta a responder y la respuesta explicativa que se da sigue estando bajo el yugo de las razones. Es decir, se intenta "explicar por qué algo pudo resultar un medio más adecuado que otro para la consecución de un determinado resultado y eso, aunque no lo queramos, no nos lleva al orden de las causas mecánicas sino que nos pone ante una provincia muy particular del orden de las razones" (Caponi 2003).

Como el propio Darwin admite, los rasgos de un individuo deben ser tomados como útiles en los especímenes, directa o indirectamente, o como útiles para alguno de sus ancestros. Esto parece ofrecernos una visión de la selección natural como un mecanismo resolutorio de problemas. Ante un entorno hostil, donde hay escasez de alimentos, depredadores, enfermedades, etc., se mantienen las mejores soluciones para los diferentes problemas. Es la escasez y la resolución para solventar sus consecuencias la que marca el destino de los individuos y no ningún determinismo físico. No se explica la causa de las variaciones, pero sí el porqué de su mantenimiento y extensión; y resulta que ese porqué es un para qué (Brandon 1990, 1996). La forma que tiene el biólogo de averiguar el porqué de un determinado rasgo es indagar en el para qué de este, qué función cumplía, para qué era útil. En toda adaptación no solo hay un qué o quién se adapta, sino también un respecto $a$ qué, y es esa unión entre lo adaptado y el entorno lo que requiere de una explicación teleológica. En definitiva, el hecho de que la estructura explicativa de las adaptaciones sea la de problema-solución (Caponi 2003) dota a tal explicación de un irremediable nexo teleológico entre las presiones selectivas y las estructuras más eficientes que se mantienen (nexo que, en cambio, no se podrá encontrar nunca con el origen de dichas estructuras).

\footnotetext{
${ }^{9}$ Para una defensa de que la teleología darwinista se expresa a través de la acudida metáfora del diseño véase Ruse (2000).
} 
Dicho esto, es oportuno recalcar que la explicación de las adaptaciones es una cuestión de elección entre las alternativas existentes:

[...] no se trata, entonces, de explicar cómo algo ocurre o actúa sino de mostrar por qué eso pudo ser mejor que otra cosa que se presentaba como alternativa. Es decir, no se trata simplemente de saber lo que algo hace, sino de saber en qué sentido lo hace mejor que alguna alternativa efectiva. La pregunta deja de ser simplemente ¿qué es lo que $\mathrm{X}$ hace? o, incluso, ¿para qué sirve X?; y, en lugar de ello, nos encontramos con una interrogación doble: ¿qué es lo que x hace mejor que z? y ¿en qué sentido lo hace mejor? (Caponi 2003, 1004)

Ahora bien, una alternativa sólo es más eficiente en relación con las demás. Por lo tanto, la selección natural solo puede llevar hacia la perfección local o relativa a las especies, es decir, en relación con el resto de las alternativas. Y con perfección Darwin se refiere a adaptación, a utilidad, siempre delimitada por el dominio de su entorno:

La selección natural tiende solo a hacer a cada ser orgánico tan perfecto como los otros habitantes de la misma comarca con los que entra en competencia, o un poco más perfecto que ellos. [...] La selección natural no producirá perfección absoluta [...] (Darwin 1988, 253)

Con esta relativización de la perfección, Darwin da el estoque definitivo a las leyes progresivas. Las especies más aptas solo lo son en la relación a su entorno y al resto de habitantes que lo ocupan. La adaptación no es prueba de la complejidad de los organismos. Se deshace del predeterminismo y también de la teleología intra-orgánica. No hay, en principio, un impulso finalista dentro del individuo. Esto suponía dejar, de una vez por todas, cualquier postura esencialista. No hay un eidos unitario e inmutable para cada especie ni un telos específico. Una vez se abre el paso definitivo al adaptacionismo, el esencialismo y el fijismo caen.

Las especies, incluso advirtiendo que son un artificio, difícilmente pueden ser delimitadas como ya decía Buffon. Darwin asumió la imposibilidad de diferenciar lo que son las variedades de lo que son las especies. "No es posible determinar la cantidad de diferencia necesaria para conceder a dos formas la categoría de especies" (Darwin 1988, 109-110). Este párrafo es fundamental para mostrar su antirrealismo:

Por estas observaciones se verá que considero la palabra especie como dada arbitrariamente, por razón de conveniencia, a un grupo de individuos muy semejantes y que no difiere esencialmente de la palabra variedad, que se da a formas menos precisas y más fluctuantes. A su vez, la palabra variedad, en comparación con meras diferencias individuales, se aplica también arbitrariamente por razón de conveniencia. (Darwin 1988, 104)

Revista de Humanidades de Valparaíso, 2019, No 14, 395-426 
Darwin creía oportuno abrazar ese convencionalismo, dar por combinaciones artificiales a las especies por poco atrayente que parezca. Asumir esto ayudará a quedar "libres de las infructuosas indagaciones tras la esencia indescubierta e indescubrible del término especie" (Darwin 1988, 569). Sin embargo, el que no haya una barrera nítida entre especie y variedad no implica que no existan las especies individuales (Sloan 2009). Tampoco existe una barrera nítida entre políticas de izquierdas y de derechas o entre ricos y pobres, pero eso no impide admitir que hay, efectivamente, ricos y pobres y políticas de izquierdas y de derechas (Sober 2011). Darwin, no podía definir o delimitar lo que era una especie, pero tampoco podía prescindir de ellas, su teorizar dependía de tal concepto, como se verá en el siguiente apartado.

Hasta ahora se ha señalado de manera general cómo la teoría de la selección natural implica un cierto punto de inflexión en lo que a la teleología en biología se refiere. También se ha subrayado brevemente qué consecuencias tiene esto para el concepto de especie. El debate acerca de si hay vestigios teleológicos y de qué tipo en la teoría darwinista ha sido rico y amplio, pero dónde enlazan la teleología y la noción de especie en dicha teoría no ha sido tratado en profundidad. Se viene argumentando desde el comienzo que las nociones de especie y finalidad no se pueden desligar fácilmente en la historia del pensamiento biofilosófico (al menos hasta Darwin). Y esa conexión en la teoría del naturalista inglés no obtiene su lado más fecundo del mecanismo de selección natural en sí mismo, sino en la conjunción de dos principios fundamentales para este: la lucha por la existencia y la superfecundidad. Por otro lado, hay otro punto fundamental donde se da dicho enlace, a saber, el principio de divergencia. Es más, Darwin necesitó acudir a una teleología determinada para desarrollar este último e intercambia el vocabulario típico del pensamiento poblacional — en el sentido que explica Mayr (1991) — por uno de corte tipológico. Por eso, el giro darwiniano, aun siendo radical, no es completo, no destruye de forma definitiva a la teleología, ni siquiera aquella que parecía enterrar. Esto es lo que se analizará en el siguiente apartado.

\section{Superfecundidad y divergencia: elementos teleológicos que necesitan un concepto realista de especie}

Como se ha venido indicando, Darwin hirió de muerte a la teleología predeterminada e intra-orgánica. Fue el causante principal del resurgimiento de aquel problema al que ya se enfrentó Kant en la segunda parte de la Crítica del Juicio: conciliar el mecanicismo triunfante en la física newtoniana con la ciencia natural de los organismos. Los organismos vivos, al ser entidades materiales, deberían poder ser explicados mediante leyes mecánicas, pero es inevitable acudir a explicaciones teleológicas, como si los organismos fueran "propósitos naturales" (Walsh 2006; Rosas 2008). Ambas soluciones no son compatibles, 
suponen una antinomia, pero es una tensión de difícil solución, a la que Kant no da una respuesta del todo satisfactoria y que, como se argumentará, Darwin tampoco terminó de cerrar.

En este apartado, se tratarán por separado dos cuestiones fundamentales: por un lado, se examinará cómo la premisa de superfecundidad es clave en la noción de lucha por la existencia y cómo esta implica un cierto posicionamiento teleológico al cumplir una labor semejante a una disposición natural. Por otro lado, se analizará cómo el principio de divergencia, que el propio Darwin consideraba como su aportación más importante junto a la selección natural, requiere de una teleología de corte determinista. Además de esto, se mostrará que nuestro naturalista acude a una noción de especie como fenómeno real y natural.

\subsection{Superfecundidad como premisa fundamental}

El uso de la idea de "selección natural" era relativamente común antes del empleo que se le dio en el Origen (cf. Zirkle 1941). Incluso el propio Darwin sabía de ella antes de lo que algunos han llamado el "descubrimiento malthusiano" de 1838. Hasta la teoría darwinista, la selección natural era un principio conservador, el mecanismo natural que se encargaba de eliminar las desviaciones, era la "policía de la naturaleza", el conjunto de procesos que permitía mantener el equilibrio en la economía de la naturaleza que ya promulgaba Linneo. El gran salto de Darwin fue hacer de este principio un proceso creativo. La selección natural dejaba de ser un procedimiento natural de extirpación de cualquier perturbación para convertirse en el motor principal del cambio evolutivo (cf. Gruber 1984).

Como ya se ha argumentado, para Darwin la selección natural no es la causa de las variaciones, sino que es un proceso de criba que permite a las variedades más aptas sobrevivir. Esto suponía desvincular de una vez por todas el origen de las variaciones de las adaptaciones. En su prematura teoría de las mónadas, Darwin seguía manteniendo el nexo entre la génesis de las variaciones y las adaptaciones, es decir, como en la teoría lamarckiana, creía que las variaciones son respuestas adaptativas. Si las variaciones fueran consecuencia de las presiones del entorno, entonces no sería necesaria ningún tipo de selección. En cambio, en la teoría de la selección natural ante la ausencia de un enlace causal entre el origen de la variación y la adaptación, lo que necesitaba era suponer un número alto de variaciones en la descendencia que le dieran a la selección natural el material necesario para trabajar. Volviendo a la metáfora del constructor, Darwin necesitaba suponer no solo un gran número de piedras con las que el constructor pueda trabajar, sino que estas tuvieran una gran diversidad de formas. Con otras palabras, necesitaba asumir un alto grado reproductivo de los seres vivos que implique importantes cifras de descendencia con gran diversidad de variaciones:

Revista de Humanidades de Valparaíso, 2019, No 14, 395-426 
La evolución de la biología y la biología evolucionista: especie y finalidad

Daniel Labrador Montero

Mientras la variación fue concebida como directamente adaptativa, únicamente podía existir una sola modificación apropiada para cada cambio en el medio. Solo después de haber descartado la idea de que las variaciones son necesariamente adaptativas se hacía necesario disponer de diferentes variaciones entre las que la selección debiera escoger. Pero cuando el número de variaciones requeridas por la teoría se hizo muy grande, el principio de la superfecundidad pasó a primer plano de atención. Deben existir muchos individuos que sirvan de «portadores» de las diferentes variaciones. Puede que la variación y la selección sean principios separados, pero ambos son aspectos de la misma realidad, un gran número de individuos que varían. (Gruber 1984, 218)

Estas dos premisas, a saber, la superfecundidad y la variabilidad, son fundamentales para la noción central de la selección natural: la lucha por la existencia. Mientras que Malthus había visto en la superfecundidad un peligro para la supervivencia de la especie humana, Darwin le dio un carácter positivo. Solo hay competencia si hay un número de individuos cuyo consumo de recursos excede la cantidad disponible de estos, y es precisamente la competencia la que provoca que solo los más aptos sobrevivan y se reproduzcan (selección), dándose así seres cada vez más adaptados a su medio. No se puede obviar que para el naturalista británico es la competencia intraespecífica la más severa y el principal impulsor selectivo, lo que le da todavía más importancia a la superfecundidad.

Hay quienes han visto en la lucha por la existencia un principio de corte claramente metafísico (Hernández-Pacheco 2014): lo vivo lucha por vivir. Hay que plantearse si es lícita la deducción de que "como se producen más individuos que los que pueden sobrevivir, tiene que haber en cada caso una lucha por la existencia", sobre todo, si tenemos en cuenta que "las causas que contienen la tendencia natural de cada especie al aumento son oscurísimas" (Darwin 1988, 115 y 117). La variación y la selección serían inocuas sin este afán de supervivencia, sin ese intento de imposición de lo individual. Esto querría decir que la vida no es resultado de la evolución, sino que es la causa (HernándezPacheco 2014, 75), es decir, no es la evolución la causa que permite la vida a través de la adaptación, sino que es la propia vida, esto es, el propio afán por vivir lo que pone en marcha a la evolución.

Sin embargo, entender la lucha por la existencia como imposición individual es desatender el carácter metafórico y amplio de tal noción especificado por el propio Darwin en el apartado 2 del tercer capítulo del Origin. Lejos de las guerras y hambrunas de Malthus, Darwin entiende la lucha por la existencia más bien como codependencia entre los diferentes organismos dentro de un "lugar en la economía de la naturaleza", y el resultado de dicha "pugna" es fundamentalmente la supervivencia reproductiva. Es decir, la lucha por la supervivencia "incluye no solo la vida del individuo, sino también el éxito al dejar descendencia", pues, al fin y al cabo, "todos y cada uno de los seres orgánicos puede decirse que están esforzándose hasta el extremo por aumentar en número" (Darwin 1988, 113 y 117).

Revista de Humanidades de Valparaíso, 2019, No 14, 395-426

(c) $(1)(9)$ CC BY-NC-ND 
He aquí, por tanto, el rol fundamental de la superfecundidad en la teoría darwinista: es una premisa indispensable y, además, una disposición natural de corte finalista. Esta premisa, en primer lugar, es de suma importancia porque la necesita para poder explicar los mecanismos selectivos basados en la competencia y, en segundo término, es una noción teleológica porque Darwin la toma como una orientación ineludible de todo ser vivo. Continuamente Darwin trata este principio como algo parecido a un fin impreso en todo organismo: "All that we can do is to keep steadily in mind that each organic being is striving to increase in a geometrical ratio" (Darwin 1859, 61). Su obra cumbre está plagada de pasajes en los que señala que los organismos se esfuerzan (strive), tienden (tend) o incluso luchan (struggle) por conseguir el mayor número de descendientes posibles. La misma forma de expresarlo utiliza en The Variation of Animals and Plants under Domestication (cf. Darwin 1868, 1-14) Dicho de otro modo, parece que Darwin considera que todos los individuos están determinados a reproducirse todo lo que puedan, y la forma en la que lo expresa y el papel que ocupa tal cuestión en su teoría va más allá de la tendencia a la replicación a la que acude el modelo genocéntrico dawkinsiano y la biología actual.

Darwin se había encontrado con la idea de "sobreproducción de descendencia" mucho antes de leer a Malthus, pero no fue consciente de su importancia teórica hasta que enlazó toda esta serie de conceptos. Por ejemplo, había leído sobre ella en los trabajos de C. G. Ehrenberg y la idea de la gran fertilidad de la naturaleza ya había sido expuesta por sus principales influencias: Erasmus Darwin, Paley, Lyell y Humboldt (cf. Gruber 1984, 216218). Por superfecundidad hay que entender "[...] el grado en que un organismo tiende a reproducir un número de individuos de su propio tipo mayor que el número vivo en cualquier generación parental dada" (Gruber 1984, 216).

Teniendo en cuenta todo lo dicho, en la lucha por la existencia darwiniana se tienen en cuenta tanto las adaptaciones individuales al entorno, por un lado, como la eficacia reproductiva, por el otro. Ahora bien, como se ha señalado, es el proclamado "esfuerzo" por reproducirse todo lo posible un elemento teórico indispensable para la tesis de la selección natural. Por esta razón, Darwin necesita asumir que la supervivencia y la existencia (y, por tanto, la lucha por ella) incluyen el éxito reproductivo (como él mismo señala en Darwin 1988, 113). ¿Cómo seguir afirmando solo a los individuos cuando parece que el mecanismo selectivo depende del afán de supervivencia a través de la reproducción? ¿Cómo explicar de forma mecanicista el impulso de lo vivo a la competencia para mantener la vida? Es necesario recordar en este punto que para Darwin la selección solo obra sobre los individuos, para el "beneficio" de los organismos. Pero, siendo estrictos, no hay razones para considerar como beneficioso para el individuo (y solía considerarlo así) el hecho de mantener sus características (hoy diríamos la promoción de sus genes) en su descendencia, a no ser que se suponga dicha finalidad como un impulso o una "tendencia" generadora de "esfuerzos" individuales. De no hacer tal suposición, se estaría dando el paso a considerar los beneficios del grupo como directos a la selección, cosa que Darwin 
no estaba dispuesto a hacer, aunque sí Wallace. Es decir, si Darwin no hubiera asumido la tesis de la superfecundidad como algo semejante a una disposición natural individual, habría algo más que una tensión entre el individualismo darwinista y dicha premisa. Sin embargo, sigue rezumando por detrás una noción realista de especie con consecuencias reales sobre el mundo, pues resulta difícil explicar dicha disposición sin entender, de alguna manera, que la especies existen.

Esta teleología basada en disposiciones naturales parece suponer una noción de especie difícilmente asumible por un antirrealista radical. Si lo de Aristóteles era un realismo moderado, se podría decir que lo de Darwin se asemeja a un antirrealismo con el mismo calificativo. Por otro lado, la teleología intra-orgánica no decae del todo con Darwin, pero esta vez aparece ocupando un papel central en la metafísica de la selección natural. Un principio metafísico que en definitiva depende del concepto de especie o, al menos, de variedad como subespecie, porque ese impulso hacia sobrevivirse a sí mismo a través de la progenie tiene como condición de posibilidad a la subespecie o a la especie. Hay que recordar que es el propio Darwin el que confirma que la lucha por la existencia incluye el dejar la mayor progenitura posible. Entonces, ¿cuál es la existencia que se pone en juego? Parece que no solamente la individual. La frase 'los más aptos dejan más descendencia' incluye el supuesto de que ser más apto implica reproducirse más, y dicho supuesto es alimentado por un concepto de supervivencia en el que se incluye la perduración de la variedad o, incluso, de la especie.

\subsection{El principio de divergencia y la maximización de la cantidad de vida}

En la teoría de Darwin hay otro principio fundamental además de la selección natural: el principio de divergencia, calificado como una piedra angular (keystone) de la teoría por el propio Darwin. Aunque tanto en El Origen como en el Species Book este principio se incluye dentro del capítulo que aborda la selección natural — pues, depende de este último - lo cierto es que la importancia que le confiere su autor es casi equiparable a la del otro gran principio, y así lo expresa en una carta a Joseph Hooker: "the "principle of Divergence,' which with 'Natural Selection' is the keystone of my Book \& I have very great confidence it is sound" (Burkhardt y Smith 1991, VII 102).

Dicho principio estaba destinado a explicar tanto la progresiva divergencia entre las variedades y especies como, también, la extinción de las especies emparentadas no exitosas. Respecto a lo primero, Darwin tenía que demostrar cómo se producen los procesos de especiación, de tal manera que las variedades poco diferenciadas (consideradas como especies incipientes) acaben dando lugar a especies bien diferenciadas. En otras palabras, tenía que explicar cómo variedades muy cercanas respecto a su tronco parental terminarían por dar lugar a especies situadas en ramas distantes en el árbol de la vida. Respecto a la extinción, debía dar con el mecanismo que explicara cómo el triunfo de dichas variedades implicaba la desaparición de las variedades y especies intermedias,

Revista de Humanidades de Valparaíso, 2019, No 14, 395-426 
así como de los antecesores. Esto conllevaba dar razón de por qué aquellos seres más divergentes, esto es, que más se alejaban de sus predecesores y del resto de variedades emparentadas tienen ventaja y más posibilidades de ser seleccionados.

Uno de los grandes escollos teóricos de Darwin fue dar con dicha razón, pues tenía que hallar el fundamento de la afirmación de que las variedades extremas tienen ventaja respecto a sus competidoras para ser seleccionadas. La respuesta que Darwin defendió es que las variedades extremas, esto es, las más diversificadas, son capaces de "apoderarse" de más cantidad y más diversos lugares en la economía de la naturaleza. O sea, que aquellos organismos más divergentes tendrían una mayor capacidad de hacerse con nuevos y diferentes nichos ecológicos (en el vocabulario actual). Sin embargo, esto abre otro abanico de preguntas de difícil respuesta: ¿por qué las variedades extremas tienen ventaja sobre aquellas con cambios más moderados a la hora de ocupar otros nichos? ¿Por qué si ocupan nuevos nichos se extinguen las variedades intermedias y los antecesores? Ninguna de las dos preguntas obtuvo una solución clara. En lo relativo a la primera, no se ofrece ningún motivo por el que ser mas divergente otorgue una mayor capacidad para ocupar otros nichos. Es más, como bien señala Richards $(2012,262)$, las características extremas suelen ser más bien perjudiciales en la lucha por la existencia. Hay que tener en cuenta que el hecho de ser divergente no tiene por qué conferir una mayor flexibilidad o plasticidad adaptativa. De hecho, esto sería más común en descendientes con modificaciones moderadas. En cuanto a la segunda cuestión, Darwin ofrece la resolución de que dichas variedades extremas mantienen los rasgos adaptativos de sus antecesores. Con esto vendría a decir que son igualmente competitivos que sus predecesores con el añadido de alguna característica valiosa nueva y que, por ello, son capaces de trasladarse de nicho, pero también de ocupar el lugar de sus predecesores provocando la extinción de estos. Sin embargo, resulta difícil explicar por qué si se ven favorecidos en los nichos nuevos iban a quedarse habitando y compitiendo en los ocupados por sus antecesores.

Por debajo de esta debilidad argumentativa se manifiesta cierta carga teleológica, principalmente respecto a la primera incógnita. Así, David Kohn (2009) intenta responder a la cuestión argumentando que Darwin propone una "selección divergente", es decir, una ampliación de la selección natural que implica que, bajo ciertas condiciones, se seleccionan las variantes más extremas. Ahora bien, ¿cómo puede afirmarse tal cosa? ¿Cómo la naturaleza iba a saber cuál es la variante más extrema? Hay que dar la razón a Richards (2012) cuando explica que esto es ir muy lejos y que la interpretación de Kohn de un principio selectivo especial solo tendría cabida bajo una naturaleza intencional y clarividente. En realidad, el verdadero núcleo del problema surge porque no se da una razón fundamentada de por qué la divergencia, cuanto más radical, es más ventajosa para ocupar nichos. Y esto se debe, como de nuevo Richards (2012) observa, a que Darwin en ocasiones abusa de la analogía con la selección artificial. No se puede obviar que, después 
de todo, la selección del criador está basada en actos intencionales y con finalidades marcadas. De esta manera, Darwin, convencido de la analogía, transporta la estructura argumentativa al principio de divergencia:

The breeder thus selects the most extreme traits and ultimately winds up with a morphologically very extreme individual. Darwin believed nature acted analogously: she chooses extreme traits at every iteration and finally produces a quite distinct species. The advantage realized would be a more secure hold on resources and greater numbers [...]. What seems to have escaped his reflective notice, however, was the salient difference between nature and the breeder: the pigeon fancier can detect extreme traits and carefully select out of his flock just those birds that display such traits and mate the individuals together. Nature, it would seem, cannot accomplish a comparable feat. (Richards 2012, 262-263)

Darwin había comprobado la idoneidad y eficacia de esta analogía respecto a otros aspectos. No obstante, en este caso se excedió. Mientras que a través de dicha analogía aún podía explicar cómo no era necesario un seleccionador ni un telos para que prevalezcan los individuos más aptos, no lo pudo conseguir para explicar cómo son seleccionadas las variedades más extremas. Ciertamente, una vez Darwin necesitó abrirse a la especiación simpátrica, el problema del swamping argument — posteriormente explicitado por Fleeming Jenkin, pero del que Darwin ya tenía cierta conciencia - tenía difícil remedio, es decir, resultaba muy complicado que una variación beneficiosa se extendiera y mantuviera en una población sin que se viera inundada con rasgos ordinarios e intermedios en pocas generaciones ${ }^{10}$. El hecho de que las variaciones de las especies incipientes pudieran verse invadidas por las modificaciones moderadas de variedades intermedias, o incluso desfavorables, iría en contra de la fuerte dinámica divergente que Darwin proponía y solo podría ser solventado tal inconveniente si la naturaleza es capaz de seleccionar las variantes extremas.

Llegados a este punto, Darwin no tuvo solo que acudir a cierto finalismo para solventar las dificultades teóricas del principio de divergencia, sino que también tuvo que dar irremediablemente a la especie la categoría de unidad descriptiva. Como explicitan Schweber (1980) y Gould (2002, 224-246), Darwin intercala con evidente incomodidad entre el individuo como unidad y la dupla variedad-especie. Esto es algo palmario cuando uno se enfrenta a las páginas que abordan el principio de divergencia. Efectivamente, Darwin no pudo mantener el nivel organísmico y explicar el principio de divergencia como una consecuencia directa de la selección natural entre individuos.

[...] his full argument demands a major contribution from species level selection (or, at the very least, strong attention to explicit sorting at the species level). I don't know that Darwin

\footnotetext{
${ }^{10}$ No hay que olvidar que no contaba con una teoría genética y, por tanto, quedaba lejos la genética de poblaciones que resolvería tal problema.
} 
La evolución de la biología y la biología evolucionista: especie y finalidad

Daniel Labrador Montero

ever grasped this need in a fully explicit way, committed as he was to the exclusivity of selection on organisms. But he recognized the crucial difficulty at several places in his exposition; and, with his usual honesty, he made his distress palpable again and again. (Gould 2002, 237)

Schweber $(1980,240)$, desde un punto de vista semejante, señala que hay una clara e inconsistente intercalación entre niveles de descripción. En la argumentación de este principio hay un continuo cambio sin enlace del pensamiento poblacional al tipológico al no haber una clara diferenciación entre lo que son las variedades intrapopupales y las subespecies geográficas. Darwin utiliza el mismo concepto de variedad en ambos sentidos de forma indiferenciada (Mayr 1992, 345). El nivel individualista se mantiene para los problemas relacionados con la lucha por la existencia y la adaptación (excepto por las observaciones anteriormente hechas), pero, al no contar con una teoría de la herencia, los problemas que englobaban cuestiones hereditarias y de variación, como son la divergencia y la especiación, necesitan del nivel descriptivo variedad-especie (Schweber 1980, 239240). Esto se puede apreciar claramente en las conclusiones que Darwin obtiene acerca de la variabilidad de los grandes géneros. Acudió incluso a las demostraciones matemáticas (cf. Browne 1980) para llegar a conclusiones tales como que los grandes géneros tienen un mayor número de variedades o que las especies actuales fueron variedades (en el sentido de subespecie) de especies anteriores. Y todo esto desvela un pensamiento en el que las categorías taxonómicas son una parte nuclear.

Una de sus grandes incoherencias — señalada por Gould $(2002,239)$ y derivada de este doble uso indiferenciado de variedad y del nexo entre los fenómenos adaptativos y de variabilidad - radica en intentar armonizar el argumento de la ventaja que obtienen los individuos con variaciones extremas con la idea de que el cálculo de dicha ventaja se obtiene de la cantidad de taxones descendientes. En otros términos, Darwin cayó en la incongruencia de defender que el cálculo del éxito individual era revelado a través del número de taxones descendientes que generaba. Es decir, el éxito de las variantes extremas implica para Darwin una capacidad para ocupar más nichos ecológicos y esto quedaría demostrado por su propagación en muchos y diferentes taxones. Sin embargo, resulta inconsistente tratar el éxito en la lucha individual haciendo referencia a categorías taxonómicas.

Todo este esfuerzo realizado por Darwin implica, como subraya Mayr $(1992,348)$, que, en cierta manera, considera a las especies un "fenómeno real de la naturaleza". No obstante, Darwin se mantiene invariable hacia la arbitrariedad entre las categorías de variedad y especie, sin que esto parezca ir en menoscabo de ciertas consecuencias realistas respecto a la existencia de las especies a lo largo de estas fundamentales páginas.

Ciertamente, y para ir cerrando esta cuestión, hay un principio rector que parece vincular de manera determinante la selección de las variantes extremas con el inevitable uso de las categorías taxonómicas: la maximización de la cantidad de vida en una región

Revista de Humanidades de Valparaíso, 2019, No 14, 395-426

(c) $(9)(9)$ CC BY-NC-ND 
dada. Su compromiso acerca de las bondades de dicho principio revela, de nuevo, cierta teleología e incluso un orden moral. Gould $(2002,229)$ llega a calificarlo de "objetivo natural", como un principio metafísico que subraya la tendencia y la virtud de alcanzar la mayor cantidad de vida en un área determinado. Y esto solo es posible a través de la divergencia, a saber, ocupando los máximos nichos posibles disponibles en una región.

El origen de dicho compromiso con las bondades de la maximización radica, como explica Schweber (1980), en el cálculo de optimización de Bentham, muy extendido en aquella época. A fin de cuentas, los ecosistemas pueden funcionar con menos especies y sin tender al mayor rendimiento. La idea de la conveniencia de una mayor diversificación para que más habitantes sean soportados en una región geográfica al ocupar más y diferentes nichos ecológicos y al ser más eficientes en el consumo de recursos es del todo injustificada. Sin embargo, solo esta idea de optimización une realmente la adaptación con la especiación en la teoría darwinista. Es solo mediante este objetivo natural que se puede entender tomar como éxito individual el dar lugar al máximo número de taxones, pues esto implicaría la ocupación de más lugares en la economía de la naturaleza, acercándose así al objetivo de la maximización. He aquí cómo esta nueva forma de teleología tiene implicaciones sobre la noción de especie, a saber, sobre las virtudes de una mayor diversificación de las especies. A más diversidad y divergencia mejor optimización de los recursos, más nichos ocupados y maximización de la cantidad de vida. En otras palabras, la diversificación de las especies o la apertura a lo ancho del árbol de la vida ayuda a cumplir este "objetivo natural" de maximización de la vida. Por tanto, el finalismo en la argumentación de Darwin no radica solo en la tendencia a dejar el mayor número de descendientes (superfecundidad), sino en que estos sean muy diversificados y den lugar a taxones diferenciados que ocupen diferentes puestos en la economía de la naturaleza. La consecuencia implícita es que dicho finalismo requiere de una noción de especie con consecuencias reales (como fenómeno natural) sobre el mundo. Teleología y especie, aunque de forma mucho más sutil y compleja, siguieron siendo elementos teóricos codependientes en la teoría de Darwin.

\section{Conclusiones}

El propósito de este artículo era ver la progresión del concepto de especie ligado a las pautas teleológicas de las diferentes teorías de los máximos exponentes en el pensamiento biológico hasta Darwin, siendo este último el núcleo central de este artículo por suponer un punto de inflexión. La encrucijada final que se presenta en la teoría darwiniana se hace pensando solo en las tesis y lenguaje del propio Darwin y no en las teorías neodarwinistas. Huelga decir que en la biología actual tales dilemas no son los mismos.

En resumidas cuentas, se ha intentado mostrar que: 1) existe una codependencia histórica entre el concepto de especie y las diferentes perspectivas teleológicas. 2) El finalismo esencialista, determinado e intra-orgánico propio de la reflexión biológica hasta

Revista de Humanidades de Valparaíso, 2019, No 14, 395-426

(c) $(9)(9)$ CC BY-NC-ND 
el siglo XVIII requería de un concepto de especie fuertemente realista y fundado en el fijismo, mientras que el paso al transformismo científico y a una postura continuista entre las especies va de la mano de una apertura a la teleología adaptativa e indeterminada. 3) Darwin se deshace del esencialismo y la teleología determinada tal y como aparecía en sus antecesores naturalistas y en las teorías imperantes, pero no suprime la teleología del lenguaje, la estructura explicativa y la metafísica que sustenta su teoría. A tenor de lo anterior, además de cierta estructura explicativa teleológica (problema-solución), se pueden encontrar aspectos de la teoría con una carga teleológica que se escapa de este terreno. Así, la premisa de la superfecundidad adquiere el carácter de disposición natural y en el principio de divergencia se encuentran dos cuestiones que revelan un alto componente teleológico: la selección de las variantes más extremas y el principio de maximización de la cantidad de vida. 4) Existen ciertas tendencias antirrealistas respecto a las especies en la obra de Darwin al no afirmarse clases naturales, pero en determinados elementos de su teoría necesita acudir al nivel de variedad-especie como unidad descriptiva y a un concepto de especie con consecuencias reales en el mundo, es decir, como un verdadero fenómeno natural. Además, se da el caso de que los dos aspectos fundamentales de la teoría darwinista en los que se desvela una teleología de corte determinista - superfecundidad y principio de divergencia - son precisamente en los que la noción de especie adquiere sus tintes más realistas.

\section{Agradecimientos}

Este trabajo ha sido posible gracias a las ayudas de carácter público para la contratación predoctoral cofinanciadas por la Junta de Castilla y León y el Fondo Social Europeo.

\section{Referencias bibliográficas}

Alsina, J. (2013). Conceptos anteriores a la propuesta del término biología: Historia de los Animales de Buffon. Filosofia e História da Biologia, 8(1): 75-90.

Álvarez López, E. (1948). De la «Philosophia Botanica» de Linneo a algunos temas fundamentales de la biología. Anales del Jardín Botánico de Madrid, 8(1): 5-87.

Aristóteles (2000). Investigación sobre los animales. Madrid: Gredos.

Aristóteles (2000). Partes de los animales. Madrid: Gredos.

Aristóteles (2010). Acerca del alma. Madrid: Gredos.

Aristóteles (2010). Metafísica. Madrid: Gredos.

Bacon, F. (1984). Novum Organum. Aforismos sobre la interpretación de la naturaleza y el reino del hombre. Barcelona: Orbis. 
Balme, D. M. (1962). ГENO $\Sigma$ and EI $\triangle \mathrm{O} \Sigma$ in Aristotle's Biology. The Classical Quarterly, 12(1): 81-98.

Barberá, Ó. (1994). Historia del concepto de especie en biología. Enseñanza de Las Ciencias, 12(3): 417-430.

Blunt, W. (1982). El naturalista: vida, obra y viajes de Carl von Linné (1707-1778). Barcelona: Ediciones Serbla.

Boecio, S. (2010). Segundo comentario a la "Isagoge" de Porfirio. En A. Tursi (selec.), La cuestión de los universales en la Edad Media. Selección de textos de Porfirio, Boecio y Pedro Abelardo. Buenos Aires: Ediciones Winograd.

Brandon, R. (1990). Adaptation and environment. Princeton: Princeton University Press.

Brandon, R. (1996). Concepts and methods in evolutionary biology. Cambridge: Cambridge University Press.

Browne, J, (1980). Darwin's botanical arithmetic and the principle of divergence, 1854-1858. Journal of the History of Biology, 13(1): 53-89.

Buffon (1749-1788). L'Histoire Naturelle, générale et particulière, avec la description du Cabinet $d u$ Roi. Edición digital en francés a cargo de Thierry Hoquet y Pietro Corsi. Disponible en http://www.buffon.cnrs.fr/

Buffon (1884). Ouvres complétes de Buffon. Nouvelle édition. París: Librairie Abel Pilon, A. le Vasseur, Succ. Disponible en http://gallica.bnf.fr/ark:/12148/bpt6k62187908/

Burkhardt, F. y Smith, S. (eds.) (1991). The Correspondence of Charles Darwin. Cambridge: Cambridge University Press.

Butler, S. (1948). Evolution, Old \& New or the Theories of Buffon, Dr. Erasmus Darwin and Lamarck, as compared with that of Charles Darwin. New York: Cornell Universy Library.

Caponi, G. (2002). Explicación seleccional y explicación funcional: la teleología en la Biología contemporánea. Episteme: Filosofia E Historia Das Ciencias Em Revista, 14: 57-88.

Caponi, G. (2003). Darwin: entre Paley y Demócrito. História, Ciências, Saúde - Manguinhos, 10(3): 993-1023.

Caponi, G. (2006). El viviente y su medio: antes y después de Darwin. Scientia Agricola, 4(1): 9-43.

Caponi, G. (2012). Kant entre Buffon y Cuvier. Filosofia e História da Biologia, 7(1): 43-53.

Corsi, P. (1988). The Age of Lamarck: Evolutionary Theories in France, 1790-1830. Berkeley: University of California Press.

Cuvier, G. (1798). Tableau élémentaire de l'histoire naturelle des animaux. Disponible en http:// gallica.bnf.fr/ark:/12148/bpt6k64769551

Darwin, C. (1859). On the Origin of Species by Means of Natural Selection, or, The Preservation of Favoured Races in the Struggle for Life. London: John Murray. 
Darwin, C. (1868). The Variation of Animals and Plants under Domestication. $2^{\circ}$ Vol. New York: D. Appleton.

Darwin, C. (1988). El origen de las especies. Madrid: Espasa-Calpe.

Darwin, E. (1794). Zoonomia or Laws of organic Life. London: J. Johnson. Disponible en https:// archive.org/details/zoonomiaorlawsof1794darw

Diéguez, A. (2012). La vida bajo escrutinio. Una introducción a la filosofía de la biología. Barcelona: Intervención Cultural.

Espinal, J. (2011). Universales, individuos e individuación en la edad media. Escritos, 19(43): 371-400.

García-Encinas, M. J. (2005). La crítica de Abelardo a otros nominalismos. Revista Española de Filosofia Medieval, 12: 179-190.

Gilson, E. (1980). De Aristóteles a Darwin (y vuelta). Ensayo sobre algunas constantes de la biofilosofia. Pamplona: Eunsa.

Gould, S. J. (2000). A Tree Grows in Paris: Lamarck's division of Worms and Revision of Nature. En S. J. Gould, The Lying Stones of Marrakech: Penultimate Reflections in natural History, pp. 115-143. New York: Harmony Books.

Gould, S. J. (2002). The Structure of Evolutionary Theory. Cambridge, Massachussets y Londres: The Belknap Press of Harvard University Press.

Gray, A (1874). Charles Robert Darwin. Nature, 10(240): 79-81. Disponible en: https://www. nature.com/nature/journal/v10/n240/index.html

Grene, M. (1974). Is genus to species as matter to form? Aristotle and taxonomy. Synthese 28: 51-69.

Gruber, H. (1984). Darwin sobre el hombre. Un estudio psicológico de la creatividad cientifica. Madrid: Alianza.

Harrison, P. (2009). Linnaeus as a second Adam? Taxonomy and the religious vocation. Zygon, 44(4): 879-893.

Harvey, W. (1651). Exercitationes de generatione animalium. Disponible en: https://babel. hathitrust.org/cgi/pt?id=ucm.5325107039; view=1up;seq=13

Hernández-Pacheco, J. (2014). Evolución, erotismo y origen de las especies. De vuelta desde Darwin a Platón y Aristóteles. Naturaleza y Libertad. Revista de estudios interdisciplinarios, (4): 63-95.

Jahn, I., Löther, R., Senglaub, K. (1990). Historia de la biología: teorías, métodos, instituciones y biografias breves. Barcelona: Labor.

Jiménez Sánchez-Escariche, E. (2000). Introducción. En Aristóteles, Partes de los Animales. Madrid: Gredos.

Kant, I. (2011). Crítica del Juicio. Madrid: Tecnos.

Revista de Humanidades de Valparaíso, 2019, No 14, 395-426

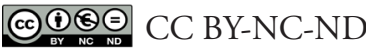


Kohn, D. (2009). Darwin's Keystone: The Principle of Divergence. En The Cambridge Companion to the Origin of Species, pp. 87-108. Cambridge: Cambridge University Press.

Lamarck, J. B. (1986). Filosofía zoológica. Barcelona: Editorial Alta Fulla.

Larson, L. (1971). Reason and Experience: The Representation of Natural Order in the Work of Carl yon Linné. Berkeley: University of California Press.

Lennox, J. G. (1993). Darwin was a teleologist. Biology and Philosophy, 8: 409-421.

Lewotin, R. C. (1982). Organism and Environments. En H. C. Plotkin(ed.), Learning, Development, and Culture, pp. 151-170. Chichester: John Wiley \& Sons.

Linneo, von C. (1737). Genera Plantarum. Disponible en: http://visualiseur.bnf.fr/ Visualiseur?Destination $=$ Gallica\&O=NUMM-096793

Linneo, von C. (1780). Philosophia Botanica. Ed. 4, no 157, p. 99. Disponible en https://www. biodiversitylibrary.org/bibliography/37651\#/summary

Linneo, von C. (1964). Systema Naturae. Facsimile of the first edition. Nieuwkoop: B de Graaf.

Lloyd, G. E. R. (1974). Early Greek Science: Thales to Aristotle. New York: W. W. Norton \& Company.

Mayr, E. (1988). Toward a New Philosophy of Biology. Cambridge: Harvard University Press.

Mayr, E. (1991). Una larga controversia: Darwin y el darwinismo. Barcelona: Crítica.

Mayr, E. (1992). Darwin's Principle of Divergence. Journal of the History of Biology, 25(3): 343-359.

Mayr, E. (2000). The Growth of Biological Thought Diversity, Evolution, and Inheritance. Massachussets: The Belknap Press of Harvard University.

Papavero, N., Pujol, J. R., Llorente, J. (1995). Historia de la biología comparada. De Descartes a Leibniz (1628-1716). México D. F.: Las Prensas de Ciencias.

Papp, D., Babini, J. (1958). Panorama general de historia de la ciencia IX. Biología y medicina en los siglos XVII y XVIII. Buenos Aires: Espasa-Calpe.

Pellegrin, P. (1987). Aristotle's classifications of animals: Biology and conceptual unity of Aristotelian corpus. Berkeley y Los Angeles: University of California Press.

Perrier, E. (2009). The Philosophy of Biology before Darwin. New York: Springer.

Richards, R. J. (2012). Darwin's principles of divergence and natural selection: Why Fodor was almost right. Studies in History and Philosophy of Biological and Biomedical Sciences, 43(1): 256-268.

Rosas, A. (2008). Kant y la ciencia natural de los organismos. Ideas Y Valores, 137: 5-23.

Ruse, M. (1973). La filosofía de la biología. Madrid: Alianza.

Ruse, M. (1987). Biological Species: Natural Kinds, Individuals, or What? The British Journal for the Philosophy of Science, 38(2): 225-242.

Revista de Humanidades de Valparaíso, 2019, No 14, 395-426

(c) $(1)(9)$ CC BY-NC-ND 
Ruse, M. (2000). Teleology: Yesterdey, Today and Tomorrow. Studies in History and Philosophy of Biological and Biomedical Sciences, 31(1): 213-232.

Schweber, S. (1980). Darwin and the Political Economist: Divergence of Character. Journal of the History of Biology, 13(2): 195-289.

Sloan, P. R. (2009). Originating Species: Darwin on the Species Problem. En M. Ruse, R. Richards (eds.), The Cambridge Companion to the "Origin of Species", pp. 67-86. Cambridge: Cambridge University Press.

Sober, E. (2003). Metaphysical and epistemological issues in modern Darwinian theory. En J. Hodge, G. Radick (eds.), The Cambridge Companion to Darwin, pp. 267-287. Cambridge: Cambridge University Press.

Sober, E. (2011). Did Darwin Write the "Origin” Backwards. New York: Prometheus Book.

Von Uexkull, J. (1945). Ideas para una concepción biológica del mundo. Buenos Aires: Espasa Calpe.

Walsh, D. M. (2006). Organisms as Natural Purposes: The Contemporary Evolutionary Perspective. Studies in History and Philosophy of Science Part C: Studies in History and Philosophy of Biological and Biomedical Sciences, 37(4): 771-791.

Wilkins, J. S. (2010). What is a species? Essences and generation. Theory in Biosciences, 129(23): $141-148$.

Zirkle, C. (1941). Natural Selection before the "Origin of Species". Proceedings of the American Philosophical Society, 84(1): 71-123 